\title{
Las figuras modélicas del mundo clásico y los mártires cristianos
}

\author{
( Coincidencias y contraste de actitudes \\ ante la vida y la muerte
}

I. LA LLAMADA DEL IDEAL

Es sobremanera incitante acercarse a contemplar esa creación que Grecia y Roma nos han legado, la imagen en que el hombre clásico se ha retratado a sí mismo no cual fue, sino cual hubiera querido ser: su imagen ideal. Es condición de todo ideal no ser posible realizarlo. Cierto. Sin embargo, aunque resulte paradójico, no hay medio más seguro para trazar la fisonomia de una época o una cultura, que conocer su repertorio de ideales ${ }^{1}$. La misión de éstos consiste en influir simbólicamente sobre la realidad, emitiendo sobre los hombres las ondas mágicas de la ilusión y la esperanza de que siempre les es posible elevarse sobre sí mismos quebrando el marco vulgar que circunscribe sus vidas.

Todo ideal elevado siempre ejerce una especie de fascinación sobre el hombre, y su acción es precisamente mucho más enérgica cuando se cierne sobre épocas dominadas por una tónica de vulgaridad y bienestar material que obnubila los espíritus. Cuando Crates de Tebas pasea su aire austero y mendicante en medio del plácido mundo burgués que nos retrata Menandro, predicando la tremenda ética de los cínicos, el rayo luminoso de la "conversión" hiere las almas de dos hermanos, Metrocles e Hiparquía, que abandonan sus cuantiosas riquezas por seguirle. El Hiparquía se convierte en la esposa de Crates, compartiendo en adelante las durísimas privaciones del idealismo cínico.

1. Véase un estudio detallado en S. Lasso de la Vega "Ideales de la Vida humana de la antigua Grecia", Helmantica, 1962, p. 23ss. 
Siglos después, el Imperio Romano contemplaba el espectáculo inaudito de unos hombres, mujeres y niños que soportaban atroces torturas antes que renegar de su fe y dirigian a las autoridades palabras que jamás éstas hubieran imaginado: "Vosotros podréis, sí, quitarnos la vida, pero hacernos daño, eso nunca podréis" ". Un lenguaje inusitado incluso entre los genios más preclaros de Grecia - Roma, se dejó oir entonces en boca de personas insignificantes, como la matrona africana Vibia Perpetua, cuando a ella y a sus compañeros se les quiere disfrazar con ornamentos paganos a punto de ser sacrificados en el anfiteatro de Cartago bajo Septimio Severo: "Nosotros hemos llegado a este trance, justamente para salvar nuestra libertad y para no tener que hacer actos como el que pretendéis, hemos entregado nuestras vidas. Este ha sido el pacto hecho con vosotros" ${ }^{3}$. Por primera vez en la Historia se escuchó

2. S. Justino, Apología, I, 2. Cf. D. Ruiz Bueno, Actas de los Mártires, edic. bilíngüe, Madrid, B.A.C., 1951. Las mismas reflexiones pone Prudencio en boca de la mártir Santa Eulalia (Peristephanon, III, 91ss.): "verdugo, quema, corta..., el dolor no penetrará hasta el alma, que está más adentro". Sobre el precedente socrático de estas ideas hablaremos más adelante. Se ha hecho célebre el ejemplo de Anaxarco, victima del tirano Nicocreonte, cuando le dice al verdugo: "curte, curte el cuerpo de Anaxarco, pues a Anaxarco mismo no le alcanzas" (citado por S. Lasso de la Vega en Héroe griego y santo cristiano, Universidad de la Laguna, $1962, p$. 69; en la $n$. 243 recoge las fuentes de la anécdota). Cuando Sócrates proclamó que los únicos bienes verdaderos son los del alma (cí. R. Adrados, Ilustración y Politica en la Grecia Clásica, Madrid, 1966, r. 512ss.) enunció un principio que seria llevado a sus últimas consecuencias por los cínicos y estoicos. Cf. S. Lasso de la Vega, Héroe griego..., p. 66ss. Véase también nuestro artículo "Evolución del concepto de libertad en el mundo clásico", Estudios Clásicos, 1968, p. 407ss.

3. Pass. SS. Perp. et Felicitatis, N. ${ }^{\circ}$ XVIII. Cf. D. Ruiz Bueno, o.c., p. 436. Sobre la relación de las Actas de los Mártires con ciertos géneros literarios paganos se ha polemizado mucho. Es cierto que en las declamaciones de las escuelas de retórica se habia creado un tipo convencional de tirano (Cf. J. Béranger, "Tyrannus. Notes sur la notion de tyrannie chez les Romains...", R.E.L., 1935, p. 87). Una variante de este género era la presentación del filósofo haciendo frente al tirano. Que haya habido influencia parcial en la fraseologia y las descripciones, etc., de este género en las Actas lo reconoce S. Lasso de la Vega (Héroe griego... p. $70, n$. 251), pero niega que debemos ver en dichas Actas sólo "literatura". Por lo demás una cierta analogía entre la fortaleza de los mártires cristianos y algunas figuras preclaras del paganismo como Sócrates. Anaxarco, Epicteto (a ello aludiremos luego), ya la habian subrayado los escritores eclesiásticos Tertuliano, Orígenes, etc. "Cuando Orígenes polemice contra Celso, no dudará en saludar en los mártires cristianos y en el propio Jesús la misma fortaleza que admira en los héroes del paganismo, y por estos mismos años, en el 250, un auténtico mártir, San Pionio, reclama como modelos a Sócrates, Aristides y al popular Anaxarco el del mortero". (S. Lasso de la Vega, o.c., p. 70 cf. D. Ruiz Bueno, Actas de los M.: p. 633). Sobre la relación entre la forma literaria de las Actas 
entonces de labios de aquella mujer la voz de la libertad de conciencia, comprada con la sangre. La Humanidad asistió al descubrimiento de uno de sus valores más preciosos: la libertad individual ". Jamás el ser humano ha atravesado trances de una tensión semejante como en aquellos tres siglos ${ }^{5}$. Un nuevo género de asombro se apoderó de muchos espíritus nobilísimos del mundo romano, que hubieron de rendirse ante los constantes ejemplos de heroismo desusado: "Yo mismo, cuando seguía las enseñanzas de Platón, oía repetir toda suerte de calumnias contra los cristianos. Sin embargo al comtemplar cómo iban intrépidos a la muerte, empecé a considerar que era imposible que hombres de ese temple vivieran en la maldad" ${ }^{6}$. He aquí cómo cuenta Tertuliano el efecto contagioso del

y el género pagano de "el filósofo ante el tirano" cf. la citada nota 251, j. 70 de la o.c. de $\mathbf{S}$. Lasso de la Vega, en que se resume la polémica y se indica bibliografía.

4. Es indudable que cuando Sócrates prefirió morir antes que abandonar su misión dio un ejemplo de libertad de conciencia llevado hasta el sacrificio de su vida. Lo desconcertante y contradictorio de su figura está en el hecho de que fue a la muerte creyendo que debia obrar asi "antes que desobedecer las leyes de la pólis". En cambio los cristianos eran conscientes del carácter revolucionario e innovador de su religión. Como dice Tertuliano (Ad nationes, 2,1,1,C.C.1, Turnhout 1954), "adversus haec igitur nobis negotium est, adversus institutiones maiorum, auctoritates receptorum, leges dominantium... adversus vetustatem, consuetudinem, necessitatem..." Cosa que por lo demás resultaba evidente a los ojos de los enemigos del Cristianismo, entre ellos el emperador Juliano o el historiador Eunapio (cf. $n$. 6) que la denunciaban como koinón kéryma contrario a las tradiciones de los patróia dógmata y los palaiói thesmói; cf. Mac Mullen, Enemies of Roman Orden..., Cambridge, Mass., Harvard Univ. Pr., 1966, p. 219ss. Véase también Lellia Cracco Ruggini, Simboli di battaglia ideologica nel tardo ellenismo, Pacini-Pisa, 1972, $p .15, n$. 30.

5. Como indicamos al final de este trabajo la preparación para la gran prueba era el estado habitual del Cristianismo en los primeros siglos. Los escritores eclesiásticos, traten el asunto que traten, siempre tocan el tema del martirio. Y los autores paganos, si hablan de los cristianos, es para recordar su actitud ante la muerte o los castigos que se les infligen. Nunca como entonces tuvo más pleno sentido la visión de la vida cristiana como milicia o como agón.

6. S. Justino, Apología, 2, 12. Claro está (y sobre ello volveremos más adelante) que no todos razonaban como $\mathbf{S}$. Justino. El rencor, la soberbia despechada, el odio, Ia incompresión o la ceguera dictaron frases despectivas a grandes escritores paganos, que -en el mejor de los casos- tratan de restar mérito o categoría de ejemplaridad al sacrificio de los cristianos: mera testarudez, inclinación al drama, resistencia teatral. Eso es lo que ve en los mártires Marco Aurelio (Pensamientos, 11, 3). El mismo Jesucristo, cuando pide al Padre que aparte de él el cáliz de la pasión, aparece a los ojos de Celso (Discurso Verdadero, 2, 24; véase la reconstrucción de R. Bader, Stuttgart-Berlín, 1940) como un ser ruin, mediocre vulgar. (Sobre todos estos testimonios cf. el comentario de $\mathrm{S}$. Lasso de la Vega, Héroe Griego..., p. 68-69). El desprecio hacia los mártires se deja sentir igualmente en autores paganos tardios. El historiador Eunapio 
ideal cristiano: "Más nos multiplicamos cuando más somos por vosotros segados. Semen est sanguis christianorum. Muchos entre vosotros exhortan a soportar el dolor y la muerte: Cicerón, en las Tusculanas; Séneca, en lo Fortuito; Diógenes, Pirrón, Calínico, y sin embargo sus palabras no hallan tantos discípulos cuantos los cristianos enseñando con sus hechos" ?

\section{il. LA FORMULACION DE IDEALES EN LAS ETAPAS HISTORICAS}

Es verdad que muchas veces los ideales sólo consiguen hacer posible una doble vida ficticia sirviendo para equilibrar ilusoriamente las deficiencias de la realidad. Pero en todo caso una cosa es cierta, y es que la proyección de ideales, como objetivo de sus más hondas aspiraciones, ha sido siempre algo consustancial al hombre. Justamente nunca se han formulado las normas supremas de una época con más patética claridad que cuando esas normas y esa época presiente que ha llegado su fin. Tal ha sido la suerte del "caballero andante", la hermosa ilusión que iluminó el mundo medieval. Sobre la realidad áspera y cruel del siglo XV se derrama la blanca ensoñación del ideal caballeresco, si bien sorprendemos ya una leve burla melancólica que viene a equilibrar el sentimiento serio de servicio a ese ideal evanescente ${ }^{8}$. Y tal acaeció, como es bien sabido, con la imagen política del estado-ciudad griego sostenido en sus postrimerías por la voz prodigiosa de Demóstenes, la figura

de Sardes (345-420 aprox.) se desata en ataques contra los monjcs cristianos por su género de vida y por el culto que tributan a los mártires, gentes a las que habian castigado las autoridades "por sus muchos delitos" (Vitae Sophist., VI, 11, 1-2, p. 38-40 en la edic. de J. Giangrande, Roma, 1956). Idéntico desdén, la misma despreocupación en concretar y probar sus acusaciones encontramos en este autor del s. IV que en Tácito, cuando en el célebre pasaje de sus Anales (XV, 44) nos refiere la persecución de Nerón. No podían faltar tampoco en el emperador Juliano las diatribas contra los mártires, unidas igualmente a las formuladas contra los monjes (véase, p. ej., la Carta $89,288 \mathrm{ss}$.). El culto a los mártires y la vida monástica provocan en no menor grado la animosidad y la repugnancia de Libanio, el sofista y retórico de Antioquía de Siria (314-393 aprox.), que había contado entre sus discípulos a S. Juan Crisóstomo, S. Basilio el Grande y S. Gregorio Nacianceno. (Cf. L. Cracco Ruggini, Simboli di battaglia..., cit., p. 113ss).

7. Apologético, 50, 12-16.

8. Cf. J. Huizinga, El otoño de la Edad Media, 8. ${ }^{a}$ ed., tr. esp., Madrid, R. de O., 1971, p. 58ss. 
tal vez más trágica de toda la historia de la Hélade ${ }^{9}$; y lo mismo antes con el ideal aristocrático ${ }^{10}$, que, próximo a fenecer, encontró dos magníficos cantores en Teognis y Píndaro.

\section{COMO ELABORO GRECIA SU MAS ALTO IDEAL HUMANO}

Huelga recordar que la imagen del héroe clásico, del hombre perfecto no ha surgido de un modo subitáneo sobre el paisaje de anhelos transcendentes del alma griega. El mito anónimo, la épica, la lírica, los trágicos, los filósofos, han ido trazando a lo largo de los siglos los rasgos de esa imagen. Lo más patético y atractivo a la vez de ese ideal es que sentimos vibrar en él toda la hondura de dolor y ansiedad infinita del pueblo que lo ha creado ${ }^{10}$ bis. "Lo más valioso en el hombre es su eterno y como divino descontento, descontento que es una especie de amor sin amado y un como dolor que sentimos en miembros que no tenemos... El hombre es el único ser que echa de menos lo que nunca ha tenido... De aquí podría partir una meditación de la felicidad, un análisis de esa extraña condición que hace del hombre el único ser infeliz precisamente porque necesita ser feliz. Eso es: porque necesita ser lo que no es " ". Sin duda una de las más afortunadas definiciones del hom-

9. Pocos han sabido contarnos todo lo que significa el gran orador como M. Fernández-Galiano en Demóstenes, Barcelona, Labor, 1947. Sobre la "idolización" de la ciudad-estado (e. d. de una "institución efímera") ha escrito páginas inolvidables A. J. Toynbee en Estudio de la Historia, tr. esp., Buenos Aires, Emecé, 1960, $t$. III, p. 480ss. Nosotros hemos tratado también sobre este tema en el articulo "Atenas y el problema de la unificación de Grecia", Archivum, (Univ. de Oviedo), 1968; y en el articulo "Comentario en torno a un libro sobre la democracia ateniense" (C. Mossé, Histoire d'une democratie: Athênes), Revista de estudios Políticos, $1973, p$. 86ss.

10. Sobre este tema tratamos en Asi Nació el Hombre Occidental, Valencia, Cosmos, 1972, Cap. II, p. 43ss. (véase la bibliografía que allí recogemos). Sobre los ideales del hombre arcaico, cf. S. Lasso de la Vega, en el artíc. citado "Ideales de la vida humana en la antigua Grecia", Helmantica, 1.962, p. 38ss. Siguen siendo fundamentales para conocer esa epoca las obras: Dichtung und Philosophie des frühen Griechentums de Fränkel y The Lyric Age of Grece de Burn (especialmente las páginas que dedica a Teognis). Sobre Píndaro (desde el punto de vista que aquí aludimos) véase Jaeger, Paideia, tr. esp, (2. ${ }^{a}$ ed. en un solo vol.), Méjico, F.C.E., 1.962, p 196ss.

10 bis. "¿Cuánto debió de sufrir este pueblo para ser tan bello!" (Palabras finales de Nietsche en su obra El origen de la Tragedia).

11. Ortega y Gasset, Una Interpretación de la Historia Universal, Madrid, 1.960 , p. 285. 
bre griego ha sido: "el eterno insatisfecho" ${ }^{11}$ bis: En su radical insatisfacción está la clave de sus logros, que han convertido aquella cultura en el modelo del hombre occidental. "La debilidad en la secreción psíquica interna del deseo trae consigo mengua de vitalidad e ineptitud para la cultura y la civilización que son, a la postre, no más que el reboso y la sobra de aquella" ${ }^{12}$. De ahí que para exp'icar el panorama desapacible, misero, que ofrecía la Siria de su tiempo haya sido ésta la razón última que supo hallar Renán: "La barbarie en este país es siempre el triunfo del beduino, del hombre que tiene pocas necesidades" ${ }^{13}$, (es decir, del hombre satisfecho). Por su parte Toynbee, al comienzo de su Estudio de la Historia ("gigantesca arquitectura que inspira temor y reverencia" en frase de Antonio Pastor ${ }^{14}$ ), al emprender la investigación de la génesis de las civilizaciones, después de excluir otras causas, pasa a describir la verdadera, recurriendo al "lenguaje de la mitología". Y entre los mitos que selecciona expone ampliamente el encuentro sobrehumano entre el Señor y Mefistófeles del Fausto de Goethe $\left(1 .^{\circ}\right.$ Parte, v. 1692-1706) explicando así las palabras de Fausto en quien simboliza a los pueblos que emprenden el camino de la civilización: "Al intentar ascender por la ladera del risco, me doy cuenta de que estoy dejando detrás de mí la seguridad. Sin embargo por la posibilidad de su conquista correré el riesgo de la caída y la destrucción" ${ }^{15}$.

\section{LAS CUALIDADES DISTINTIVAS DEL HOMBRE SUPERIOR}

\section{FIDELIDAD A LOS PRINCIPIOS ETICOS HASTA LA MUERTE}

\section{A) El ejemplo de los héroes del mito.}

En la figura del héroe veremos plasmada esa trayectoria que recorrió la cultura clásica hasta las cumbres del más elevado ideal,

11 bis. Cf. S. Lasso de la Vega, Héroe Griego... Univ. de la Laguna, 1.962 , p. 46 .

12. Ortega y Gasset, "El Espectador", T. II, Obs. Compls., Madrid, Rev. Oc., 1.954, p. 290.

13. Mélanges Religieux et historiques, p. 72. (Citado por O. y Gasset, véase la nota precedente).

14. A. Toynbee, Cómo la Historia grecorromana ilumina la Historia Universal, Univ. de Madrid, Facultad de F. y Letras, 1.952, p. 10.

15. Estudio de la Historia, Compendio por D. C. Somervell, tr. esp., Buenos Aires, Emecé, 1.952, p. 81. 
que ha pasado a enriquecer el tesoro de nuestra cultura. El héroe vive en la acción que le ha de proporcionar el premio al valor: la gloria inmortal. Así lo declara Heracles a Filoctetes (al final del drama sofocleo de este título): "piensa en los trabajos que afronté y conseguí gloria inmortal" ( $v .1419-20)$. En el héroe es preciso distinguir ${ }^{16}$ dos rasgos peculiares: 1) prefiere morir a ser traidor a sus principios y 2) está dispuesto a vivir en el dolor para probar su heroísmo. Así Aquiles, aunque sabe que ello significa su muerte prematura, participa en la guerra de Troya y se enfrenta con Héctor. Así Eteocles, figura "la más bella sin duda de todo el teatro griego", como dice P. Mazon ${ }^{17}$. Layo, Edipo y Polinices habían sacrificado el país a sus pasiones. La gloria de Eteocles está en entregarse totalmente a él. El llamamiento a sus conciudadanos del comienzo de la pieza da el tono a su papel en toda ella. Sabe que de los hombres no recibirá más que la ingratitud, porque al fin es un maldito; sobre él pesa la angustia no sólo de la muerte temprana sino también del crimen inevitable, y siente continuamente a su lado a Ara, la terrible deidad. Sin embargo, a ella a la vez que a Zeus solamente les pide una cosa, la única que le preocupa hondamente: el bien de su ciudad ${ }^{18}$. Sólo experimenta un momento de debilidad al encontrarse con su hermano, (v. 657 ss.). Pero al punto se sobrepone. Pues el crimen que va a cometer es un deber fatal, y al caer también él mismo en el suelo, desaparecerá la raza maldecida de Apolo. En medio de su rudeza y sus sarcasmos dirigidos a las mujeres atemorizadas, y en medio de aquellas explosiones en que se mezclan las pasiones más nobles y las más criminales, Eteocles aparece sobre todo como la encarnación del amor a su ciudad, amor llevado hasta la suprema abnegación.

\section{B) El ejemplo de Sócrates. Su resonancia en los medios cristianos $y$ estoicos.}

Otro héroe que prefiere morir antes que ser infiel a su misión es Sócrates ${ }^{19}$. Sócrates es modelo del sabio que sabe morir, como revelan sus mismas palabras ${ }^{20}$ : "Estaría bien que en Potidea, Anfí-

16. Cf. S. Lasso de la Vega, Héroe Griego, p. 37 ss.

17. "Les Sept contre Thèbes", Notice, p. 106. Eschyle, T.I, Paris, L.B. L., 1.953.

18. Siete C. Teb., v. 69ss.

19. Cf. S. Lasso de la Vega, o. c., p. 39ss.

20. Platón, Apología, 28 c. 
polis y Delio me hubiera yo mantenido en el puesto que los estrategos me señalaron, aun con peligro de muerte, y cuando Dios me manda vivir como filósofo examinándome a mí y a los otros, abandonara mi puesto por miedo a la muerte o a cualquier otra cosa". De ahí su resonancia extraordinaria no sólo en los medios filosóficos posteriores sino también entre los cristianos. Cuando San Justino en su Apología dirigida hacia el año 150 a Antonino Pío, M. Aurelio y $\mathrm{L}$. Vero, les dice: "Vosotros podréis quitarnos la vida, lo que no podéis es dañarnos", recoge el pensamiento fundamental de la doctrina socrática ${ }^{21}$, según el cual el único mal verdadero no es la muerte sino el perjuicio del alma. Así pudo decir San Justino ${ }^{22}$ que Sócrates fue cristiano antes de Cristo, por haber vivido conforme al lógos (a la razón). El apologista lleva aún más lejos la semejanza entre Sócrates y el mártir cristiano: Sócrates con razonamiento verdadero intentó apartar a los hombres de la tiranía de los demonios y por eso fue condenado. Lo mismo hacían los mártires apoyados en su fe en el lógos que se hizo hombre, Jesucristo. "Y vosotros, arrastrados por pasión irracional y por azote de perversos demonios, nos castigáis sin formación de juicio" ${ }^{23}$. Más aún, S. ApoIonio, martirizado bajo Cómodo, llega a comparar a Sócrates con Jesucristo: "A la manera como los sicofantes atenienses calumniaron contra toda justicia a Sócrates..., así algunos hombres malvados calumniaron a nuestro Maestro" ${ }^{24}$.

Ya antes el ejemplo de Sócrates había encontrado fervientes imitadores entre los filósofos que le siguieron. Entre ellos Epicuro ${ }^{25}$, que soporta sus dolencias heroicamente y llama bienaventurado el día de su muerte. $Y$ sobre todo los adictos al estoicismo ${ }^{26}$, como Séneca y Peto Trasea, ejemplo inaudito de entereza bajo Nerón, en medio de la común cobardía del Senado. Su amigo Aruleno Rústico y su yerno Helvidio Prisco también supieron dar pruebas de la misma libertad de espíritu.

21. Véase la $n .4$.

22. Apologia, $I, 46$.

23. Apología, I, 5.

24. Actas de su martirio, N.o 41; cf. D. Ruiz Bueno, Actas de los mártires, p. 371.

25. Cf. S. Lasso de la Vega, o. c., p. 39.

26. Cf. S. Lasso de la Vega, $i b ., p .40$. Véase la descripción que, siguiendo a Tácito, hace Lorenzo Riber (en la Introducción a su traducción de las Obras Completas de Séneca, Madrid Aguilar, 1957, p. 38ss.) de la muerte del filósofo cordobés y de otros varios estoicos sacrificados por Nerón, que recuerdan por su entereza y serenidad el ejemplo de Sócrates. 
C) El ejemplo de los mártires cristianos. Su enjuiciamiento entre los escritores paganos.

M. Aurelio ${ }^{27}$ resalta la grandeza del hombre que sabe esperar serenamente la muerte con aquellas palabras: "¡Qué grande el alma que está pronta cuando llega la hora de separarse del cuerpo"! Pero no sabe si el alma a continuación se esfuma como la niebla en el aire, o se extingue como una chispa o bien va a habitar a algún lugar ignorado. Los cristianos en cambio en virtud de la firmeza de su fe en el destino del alma, se mostraban prontos a morir. Esto era lo que desconcertaba a aquel emperador ${ }^{28}$. $\mathrm{Y}$ al desconocer el secreto de su impavidez la explica como mera obstinación, espíritu de oposición y exhibicionismo ${ }^{29}$. Esta incomprensión o despecho ante una grandeza de ánimo que se mostraba superior a su orgullo estoico, fue quizá la causa de su crueldad patente, p. ej., en la respuesta que dio el año 177 al gobernador de la Lugdunense sobre el modo de proceder con los cristianos de Lión: "los que persistieran en la confesión de su fe debían ser muertos a palos". Crueldad que motiva la grave acusación de Dom Leclercq: "Eso es lo que había imaginado el dulce $M$. Aurelio para la ejecución de los cristianos, haciéndoles sufrir todo el tiempo posible. Toda su hipocresia se revela en este rasgo" ${ }^{30}$. Es digna en cambio de notar la ferviente admiración que muestra ${ }^{31}$ Renán por la carta de las Iglesias de Lión y Viena en que se relata el martirio de las víctimas de

27. Pensamientos, 11, 3 .

28. Sobre la opinión de $M$. Aurelio y otros escritores paganos acerca del martirio cristiano ya hemos hablado en la $n$. 6 .

29. Claro está que existe una razón profunda para la incomprensión de $\mathbf{M}$. Aurelio y de otros como él. S. Lasso de la Vega ha sabido exponerla magistralmente en la $p$. 68 y ss. de su o.c. Héroe Griego y Santo Cristiano: Hay una diferencia fundamental entre la fortaleza del sabio pagano y la del mártir cristiano. En el momento decisivo de la prueba el sabio afirma su valor de hombre, su paciencia y confianza de hombre, su grandeza de hombre. En la prueba decisiva del martirio, el cristiano se abandona a su Dios. Es fuerte porque en él se afirma la fuerza de Dios. "Al estoico que avanza sereno e impasible hacia la muerte, las Actas de los mártires oponen la estampa trágica de los gritos de esperanza y debilidad, de triunfo y dolor de los testigos de la fe en Cristo... Los filósofos paganos, testigos de la sabiduría en medio del tormento y de la muerte, enjuician severamente a los mártires cristianos. No encuentran afinidad entre la sabiduría griega y el ideal de esas gentes de ínfima laya" (ib., p. 69-70.

30. DACHL, 10 I, Col. 100, n. 3. En su Apología (I,2,2) le había escrito S. Justino a M. Aurelio: "Por todas partes estáis oyéndoos llamar piadosos y filósofos y guardianes de la justicia; pero que lo seáis en efecto es cosa que habria de demostrarse".

31. Marc Aurele, Paris, 1.882, 2. ${ }^{\mathrm{a}}$ ed., p. 340 y 329 . La carta de las 
su admirado emperador, cuya incomprensión rechaza de plano: “...Jamás se ha trazado cuadro más impresionante del grado de entusiasmo y abnegación a que puede llegar la naturaleza humana. Es el ideal de martirio con el mínimo de orgullo posible de parte del mártir. ...Los mártires de Lión son profundamente católicos por su moderación y su ausencia de todo orgullo, e. d., de toda teatralidad, de todo afán de representar una tragedia".

Más ecuánimes y serenos, ya que no entusiastas, se mostraron Epicteto $^{32}$ (60-140) y Galeno (124-200) al reconocer "las poderosas fuerzas morales que actuaban en los mártires cristianos" ${ }^{33}$. Sólo dos tipos de hombres, según Epicteto, son capaces de no temblar ante un tirano: un loco y los "galileos", que lo tienen por costumbre ${ }^{34}$. "Si dándose uno cuenta de la guardia y de sus espadas se presenta ante el tirano porque justamente quiere morir, ¿qué tirano, qué guardia ni qué espada podrán atemorizar a tal hombre? Pues bien, si puede uno por locura llegar a tal disposición de ánimo, por costumbre llegan a ella los "galileos". La Historia anteislámica escrita por Abulfeda (m. 1331) y traducida al latín en 1831 por Fleischer, nos trasmite el juicio de Galeno ${ }^{35}$ : "La mayor parte de los hombres necesita que se les instruya con mitos como en nuestro tiempo vemos a los hombres que se llaman cristianos fundar su fe en tales narraciones. $Y$ sin embargo hacen cosas que no desdicen de un verdadero filósofo. Pues cómo desprecian la muerte es algo que tenemos ante nuestros propios ojos".

\section{LAS CUALIDADES DISTINTIVAS DEL HOMBRE SUPERIOR}

II). LA PRUEBA DE LA FOFTALEZA EN EOPORTAR EL IOLOR

A) El ejemplo de los héroes del mito.

Al plantearse el problema del suicidio, Eurípides ${ }^{36}$ concluye:

Iglesias de Lión y Viena se contienen en Eusebio, Histor. Ed. V,I,3-63. La recoge D. Ruiz Bueno en Actas de los Mártires, Madrid, B.A.C., 1963, 2. ed. p. 327 ss.

32. Sobre el carácter más bien frío y ambiguo de su dictamen véase la nota 34 .

33. D. Ruiz Bueno, o. c., p. 153.

34. Episc. Dissert., 4,7,6, Nótese (como advierte $S$. Lasso de la Vega, Héroe Griego, $p$. 68) que si Epicteto no despreció a los cristianos, tampoco los alaba abiertamente. $\mathrm{Y}$ parece contraponer su conducta como actitud irracional o irreflexiva a la que dicta la razón.

35. Citado por D. Ruiz Bueno, o.c., p. 154-5.

36. Suplicantes, 802-803. 
"cuando se sufre de males imposibles de soportar, es mejor morir". Pero en el Heracles hace hablar a Teseo disuadiendo al protagonista de su intento de suicidarse tras haber matado, en un acceso de locura, a su mujer y a sus hijos. Heracles reflexiona y se sobrepone a aquella tentación: "Renunciar a la vida es crimen cobarde. Seré fuerte y viviré" ${ }^{37}$. Sófocles influido por la obra recién citada de Eurípides ${ }^{38}$, nos presenta ya al mismo Heracles ${ }^{39}$ dando análogos consejos a Filoctetes. Así pues Heracles, prototipo del héroe infortunado, se ha convertido también en el modelo del héroe paciente ${ }^{40}$.

La necesidad de un modelo heroico de paciencia la sintió Grecia desde edad temprana. Nadie como el griego arcaico acertó a expresar la angustia del hombre desvalido ${ }^{41}$ : "Los seres humanos no tienen conocimiento del futuro, sino que - criaturas efímerasvivimos como el ganado, totalmente desconocedores de cómo efectuará la divinidad cada cosa". Así se expresa Semónides de Amorgos. Ante aquellos poetas se despliega constantemente el panorama trágico de la impotencia humana, expuesta siempre a cualquier "acto de fuerza" del destino ${ }^{42}$. Sin embargo, no se ha de caer en una parálisis fatalista; no se ha de renunciar a la acción, aunque el éxito no dependa del propio esfuerzo. Cuando se abata sobre nosotros el fracaso o la desgracia, debemos mantener la esperanza de que aquello ha de pasar, de acuerdo con la ley de la sucesión periódica de momentos felices y amargos imprevisibles (la ley del "ciclo de las cosas humanas") según las palabras de Arquiloco: "los dioses nos dieron un remedio contra los males incurables, el esfuerzo resistente" ${ }^{43}$. Por eso Grecia descubrió pronto como su

37. Heracles, 1347 ss.

38. "El Filoctetes de Sóflocles es del año 409 y no parece improbable que haya sufrido alguna influencia procedente del Heracles de Eurípides, que podemos fechar... entre los años 421 y 4.15". (S. Lasso de la Vega, Héroe Griego..., p. 44).

39. Filoctetes, 1419-20 (pasaje citado al comienzo del Apartado IV).

40. Sobre Heracles, símbolo moral de la fortaleza resistente y paciente, convertido en patrono de los filósofos cínicos y estoicos, cf. S. Lasso de la Vega, Héroe Griego..., p. 45 ss.

41. Semónides de Amorgos, fr. 1,1 ss. Tal vez la visión más desolada del desvalimiento del hombre se contenga en la obra de Pindaro. Cf. F. Galiano, El concepto del hombre en la antigua Grecia (obra colectiva), Madrid, 1955, p. 35 ss.

42. Cf. nuestro libro Asi nació el hombre occidental, $p .46$.

43. Fr. 7, $7 \mathrm{ss}$. 
héroe más representativo a Ulises, designado con frecuencia "el paciente (polytlas), pero sobre todo Heracles, que con sus "trabajos" logró la inmortalidad. Más tarde será el modelo preferido de los cínicos y el héroe del pueblo. Heracles, a diferencia de Sócrates, no es el sabio teórico que busca su felicidad en el lógos; por el contrario, su maestro es el dolor y ese su carácter de héroe de la paciencia hizo que fuese también escogido como ideal por los estoi$\cos ^{44}$.

B) El ejemplo del filósofo estoico. (La nueva concepción de la divinidad)

En la pieza antes señalada (el Heracles de Euripides) encontramos planteado el misterio sobrecogedor del dolor humano, al que la filosofía estoica llegará a aportar la más sublime solución, que parece inspirada en el Cristianismo.

Tradicionalmente el sufrimiento se consideraba como castigo, incluso hereditario, de un acto de hybris (o desmesura). No obstante, la enseñanza profunda de la tragedia citada, y sobre todo la doctrina de los estoicos, rechazan semejante explicación. Heracles a su regreso del Hades, a pesar de no haber cometido ningún acto de hybris, se ve reducido a la locura, que le impulsa a matar a su mujer y a sus hijos. Al abandonar el héroe la escena, aparece Iris para dar explicación de la desgracia que aflige a aquél: tal es la voluntad de Hera ${ }^{45}$. A primera vista creeríamos encontrarnos ante un caso de "envidia" de los dioses, despechados ante la felicidad humana. Heracles tiene un primer impulso de rebelión y es cuando intenta suicidarse: "Me voy al Hades" ${ }^{47}$, dice contestando a la pro-

44. Cf. en la nota 40 la o.c. (y $p$. c.) de $\mathbf{S}$. Lasso de la Vega con la bibliografía que recoge en las notas 138 y 140 . Tal era la imagen que inspiró a Juvenal aquellos célebres versos, resumen del ideal estoico (Sat. $X, v .356 \mathrm{ss}$.$) :$

"Orandum est ut sit mens sana in corpore sano;

fortem posce animum, mortis terrore carentem...

...qui ferre queat quoscumque labores, nesciat irasci, cupiat nihil, et potiores Herculis aerumnas credat saevosque labores et venere et cenis et plumis Sardanapalli".

45. Heracles, 827 ss.

46. Sobre la "envidia" de los dioses, celosos de la felicidad humana (idea típica de la mentalidad arcaica desde Homero a Heródoto), cf. $\mathbf{S}$. Lasso de la Vega, Héroe Griego, p. 51, donde recoge toda una serie de testimonios.

47. Heracles, 1247. 
puesta de Teseo. Pero los consejos de éste logran calmarle: "Dada su vida de insignes hazañas, no debe comportarse como un hombre vulgar ni hacerse acreedor a la reputación de cobarde" ${ }^{48}$.

La raíz para resolver el problema planteado está en el modo de concebir la Divinidad que tenían los griegos. Superada la noción politeísta, vulgarizada (los dioses son los kréisones de Homero, arbitrarios y todopoderosos), se alcanzó lentamente una noción depurada, espiritualizada: Se trata de un dios interior ${ }^{49}$ que se ha constituido en ideal del hombre y es capaz de someterle a las pruebas de la virtud. De acuerdo con la primera noción, cuando el hombre justo, sin haber cometido hybris, se ve sometido al infortunio, entonces aparece como víctima de la "envidia" de los dioses. Tal concepción conduce naturalmente al fatalismo. La otra noción es la que lleva al hombre a ver en la Divinidad el atributo de la Providencia. Ya en Homero, Hesíodo, Píndaro, se nos repite con frecuencia que Dios es sabio y que los dioses gobiernan el mundo. Sin embargo, era preciso esperar al Estoicismo para que se nos expusiesen ampliamente todas las consecuencias de aquel atributo divino. Establecida la Providencia, el estoico propugna ante todo confianza absoluta en la misma y su misión sin reservas. Es lo que en el fondo nos propone la máxima de Cleantes de Asos: "Vivir de acuerdo con la naturaleza", es decir, cumplir la ley que está fijada en el cosmos, no resistir a las decisiones del destino ${ }^{50}$. Nuestra fe-

48. Ib., 1348.

49. Eurípides, el dramaturgo que proclama el "absolutismo ético", de acuerdo con un fragmento del Belerofonte (Nauck., fr. 292, 7): "si Ios dioses hacen algo vergonzoso, no son dioses", ataca los mitos que ofrecen una versión arbitraria, injusta o inmoral de la divinidad. Pero su actitud no es meramente negativa. Este poeta inicia el proceso de interiorización de lo divino en el hombre, tema de tanta transcendencia en la filosofía posterior, particularmente en Platón y la Estoa. Dios aparece identificado al espiritu del hombre: "Nuestro espíritu en cada uno de nosotros es Dios". (Nauck, fr. 1018). Dios instalad.o en el corazón del hombre: el dramaturgo pone en boca de Teónoe, la profetisa de la $\mathrm{He}$ lena, aquel verso magnífico: "Un santuario grande de justicia mora en mi naturaleza" (v. 1002). Este proceso de interiorización de la divinidad había de culminar en las sublimes reflexiones de Séneca (Epist. XII, 1): "prope est ad te Deus, tecum est, intus est", y de Epicteto (Dissrt., I, 14; 13ss): "cuando hayáis cerrado las puertas y oscurecido la casa, recordad que no podéis decir que os encontráis solos, porque no lo estáis, sino que Dios se halla en vuestro interior y en vuestra alma". (Cf. nuestro artículo, "Evolución del concepto de Nomos...", IMiscelánea Comillas, 1969, p. 20 ss.). Véase también J. Pepín, Idées grecques sur l'homme et sur Dieu, Paris, 1971, ("Le divin en nous", p. 5 ss.).

50. Cf. Estobeo, 2, 77, 16 Wachsmuth.- J. von Arnim, Stoic. Vet. 
licidad será imposible sin la sumisión a la Divinidad que ha trazado el destino de cada hombre. De ahi la célebre frase de Cleantes en el himno a Zeus: "¡Oh Zeus y Destino, conducidme" ${ }^{51}$.

Cuando el Estoicismo se enfrenta con el problema del mal, comienza anteponiendo los intereses del bien común, cuyo logro puede justificar el mal privado. El infortunio individual puede contribuir al bien general. El héroe paciente ofrece siempre un espectáculo edificante a los ojos de la Humanidad. Frente a los dioses de Homero, habitualmente despreocupados de los mortales en medio de sus deicias del Olimpo, el dios de los estoicos contempla al héroe y se goza en verle vencer la prueba. No es la "envidia" de los dioses la causa del infortunio: la Divinidad no odia al héroe ni se muestra indiferente a su dolor, sino que el héroe, con sus sufrimientos que menosprecia, da testimonio de los verdaderos bienes, que son los del alma. "Al negar, contra Aristóteles, que la virtud y la felicidad del sabio requieren los bienes exteriores, y convertir la virtud en una disciplina exclusivamente interior, el auténtico sabio será siempre rico, porque posee el único verdadero bien que es la virtud; será siempre todopoderoso, porque nada sucede en contra del Destino, con el cual él está de acuerdo; será siempre libre, porque voluntariamente se ha sometido a ese destino, y como virtuoso que es, será siempre feliz" ${ }^{52}$.

\section{C) La prueba del dolor para el cristiano.}

No es sólo en el momento supremo de la muerte cuando el mártir demuestra el temple heroico de su virtud sino también en las inacabables jornadas de la cárcel cuyo horror describe elocuentemente D. Ruiz Bueno ${ }^{53}$. "Sin la más leve idea de la higiene, con el

Fragm. 3, 5 y 3, 12. Véanse los pasajes relacionados con este punto recogidos en S. Lasso de la Vega, Héroe Griego, p. 63, n. 221. Como decimos en el artículo citado al final de la nota precedente ( $p$. 28), "en la doctrina estoica la libertad humana se ve limitada primeramente por la Heimarmene, que se identifica con la Providencia, cuya voluntad el sabio acepta espontáneamente. La Heimarmene en esta doctrina no es la potencia ciega que contraria a la voluntad humana, sino que es la Providencia que desea el bien de sus criaturas". Un magnífico estudio sobre "La libertad del sabio en Séneca", obra de Luis Martínez Gómez, se contiene en la Rev. Pensamiento, 1965, $p$ p. 379 ss. v. 1.

51. J. von Arnim, Stoic. Vet. Fragm., 1, 527. Cleantes, Himno a Zeus,

52. S. Lasso de la Vega, o.c., p. 67-68.

53. O.c. p. 130 ss. 
más absoluto desprecio de la vida del infeliz que entraba en la mansión de la sombra, sin régimen alguno de alimentación, mantenerse alli cuando una palabra bastaba para recuperar la libertad y la luz, era, en verdad, multiplicar a cada momento la gloria y la corona del martirio" ${ }^{54}$. Así se explican aquellas palabras de $\mathrm{S}$. Cipriano a unos cristianos encarcelados ${ }^{55}$ : "La primera y única confesión hace ya bienaventurado al cristiano. Vosotros la repetís cuantas veces, invitados a salir de la cárcel, por vuestra fe y valor preferís la cárcel a la apostasía. Tantas son vuestras glorias, cuantos días pasan; cuantos meses corren, tantos son los aumentos de vuestros méritos. Una sola vez vence el que padece inmediatamente. Mas el que sufriendo una pena permanente lucha diariamente con el dolor y no es vencido, cada día es coronado".

Lo que presta su grandeza peculiar al martirio cristiano ha sido expresado por Lactancio de esta manera "5.: "Gloríense los romanos de un Mucio o un Régulo...; he aquí que, entre nosotros, el sexo débil y la edad frágil se deja desgarrar y abrasar por todo el cuerpo, no por necesidad, pues pudiera, si quisiera, evitarlo, sino por voluntad, pues confía en Dios". Es decir, que lo que había sido el ideal abrazado sólo por un grupo de almas privilegiadas en el mundo clásico, se ha convertido en el cristianismo en el ideal de todo el pueblo. La preparación para la gran prueba era el estado habitual del cristianismo en los primeros siglos. Como hace notar G. Boissier, del siglo I al III todos los escritores eclesiásticos, traten el asunto que traten, siempre tocan el tema del martirio. $Y$ los escritores paganos, si alguna vez mencionan a los cristianos es para recordar su actitud ante la muerte, o simplemente los castigos que se les inflige. Por ejemplo Celso, "que escribe tras uno de esos ataques brutales (hacia el a. 178) que él tiene por eficaces, no puede menos de decirles en tono de triunfante insolencia: "Si quedáis aun tres o cuatro, errantes y escondidos, se os busca para llevaros al suplicio" ${ }^{57}$. Por eso, nunca como entonces tuvo más pleno sentido la visión de la vida cristiana como una milicia o como un agón en que habia de mostrarse la intrepidez espiritual hasta el grado supremo del heroísmo. ¡Cómo desborda este fervor agonal en el redactor de la famosa carta de las iglesias de Lión y Viena cuando des-

54. Id., ib., p. 131.

55. Epist. 27, 3. (Citado por D. Ruiz Bueno, o.c., p. 131)

56. G. Boissier, La fin du paganisme, Paris, 1891, I, p. 392. 
cribe a la esclava Blandina en el tormento revestida "del invencible atleta que es Cristo! ${ }^{58}$. "Por San Pablo sabiamos que todo cristiano es un luchador; mas dar a Cristo mismo el nombre de atleta es audacia del redactor de esta carta, escrita a la verdad bajo la obsesión de la imagen de lucha y combate" ${ }^{59}$. Este es el secreto de toda la grandeza del martirio cristiano. La confianza que tiene el mártir de no estar sólo en la prueba. Cristo le asistirá como había solemnemente prometido, hasta el punto de que "el cuerpo del mártir es una pura llaga y tumor, mas en él sufre Cristo y realiza gloriosas hazañas" " ${ }^{60}$. La absoluta seguridad que tenía el mártir de que sería auxiliado por Cristo se revela en la respuesta de Santa Felicidad al carcelero que se burlaba al verla quejarse por los dolores de parto en la prisión: "Quae sic modo doles, quid facies abiecta bestiis?Modo ego patior quod patior. Illic autem alius erit in me qui patietur pro me, quia et ego pro illo passura sum" ${ }^{61}$. San Justino, el gran admirador de Sócrates, descubre el profundo contraste entre los dos ideales, cuando dice en su Apologia (II, 10,6): "A la verdad, a Sócrates nadie le creyó hasta el punto de morir por (su doctrina); mas a Cristo... no sólo le han creído hombres amantes del saber... sino hasta artesanos y gentes ignaras que han menospreciado la gloria, el miedo y la muerte".

\section{CONCLUSION}

Son indudablemente profundas las diferencias que separan a dos de las figuras más representativas de los ideales de la cultura clásica y el Cristianismo: el héroe-sabio estoico y el mártir cristiano, diferencias que ha sabido resaltar con toda nitidez $\mathrm{S}$. Lasso de la

58. Cf. D. Ruiz Bueno, o.c., p. 325.

59. Id., $i b$.

60. "Carta de las Iglesias de Lión y Viena"; (Eusebio, Hist. Ec., V, I, 3-63) (Descripción de las torturas del mártir Santo, p. 333 de la o.c. de D. Ruiz Bueno). Como dice S. Lasso de la Vega (Héroe Griego, p. 71), "en la prueba decisiva del martirio, el cristiano se abandona a su Dios. Es fuerte porque en él se afirma la fuerza de Dios... Es paciente porque espera en Dios... La parresía, la franqueza y altivez con que el sabio, que se sabe superior al tirano, habla a su verdugo, adviene ahora confianza en Dios. La muerte heroica del sabio exalta al Hombre; el martirio del cristiano exalta a Dios. Bajo la similitud de las apariencias se esconde una diferencia fundamental, un elemento inédito de muy difícil compresión para una mente genuinamente helénica, una esencial novedad".

61. Pass. SS. Perpet. et Felic., XV. Cf. D. Ruiz Bueno, o'c., p. 434. 
Vega ${ }^{62}$. Sin embargo, hemos podido ver también los inmensos progresos logrados a lo largo de los siglos por las mentes más nobles de Grecia y Roma en la búsqueda del tipo humano más perfecto y en la concepción de la Divinidad. Nadie con más empeño que algunos de los primeros apologistas, mártires y escritores eclesiásticos llemó la atención sobre el parentesco espiritual que les unía a aquellas almas elevadas que había producido el mundo grecorromano, como Sócrates y Séneca ${ }^{63}$. En las líneas precedentes hemos recogido algunos de sus testimonios. Concluiremos, pues, con S. Basilio, Orígenes, Clemente de Alejandría, S. Justino, S. Apolonio y muchos tratadistas modernos como Peterich, Festugière, Prümm ${ }^{64}$ diciendo que en muchos aspectos el Cristianismo ha sido el coronamiento y sublimación de lo más puro que nos ha legado la cultura clásica. Entre los ideales de aquella cultura y los cristianos no ha habido solución de continuidad.

Isidro Muñoz VALLE

Catedrático de griego de

la Universidad de Valladolid

62. Cf. las notas 29 y 60 .

63. Sobre Séneca véase $\mathrm{S}$. Lasso de la Vega, Héroe Griego, $p$. 66, $n$. 234. En nuestro libro Actitudes ante la cultura clásicà, Madrid, 1971, hemos tratado de las relaciones entre la cultura clásica y el cristianismo en las págs. 63-64 (con amplia bibliografia en la $n$. 2) y 117. Se ha hecho especialmente célebre la frase de Tertuliano" "Séneca saepe noster". De anima, 20; $P L, 2$, 724.

64. Cf. nuestro libro citado en la nota precedente, p. 118. 